By JOHN E. CLEMONS

\title{
Teaching Bibliographic Sources and Styles to Graduate Students
}

$\mathrm{A}^{\mathrm{n}}$ RECENT ARTICLE called attention to the movement existing in numerous institutions to insist "on the formal study of bibliographic materials as a part of the graduate school program."'1 There are evidences in library literature that bibliography is being taught to advanced students in various disciplines. ${ }^{2}$ However, a cursory review of the literature fails to reveal discussion of a program similar to the course that began in 1948 at Florida State University. In this course, the bibliographic sources common to research investigation in all subject areas and the bibliographic styles appropriate for the varied types of library materials are presented to give students confidence in two major aspects of research: the searching and the citing of library sources. Perhaps this is a novel experiment in that all graduate students, regardless of subject specialization, attend the same course.

The incentive for the development of such a course in the curriculum of the Florida State University Graduate School was the widespread belief among faculty members that graduate students needed to become familiar with: (1) the bibiographic sources which are common to all research fields, the use of which is necessary to reflect an exhaustive and

1 Katherine S. Diehl, "Formal Bibliography in the Upper Division," CRL, XVI (1955), 386.

${ }_{2}$ An illustration of the efforts by one technological group is discussed in "Teaching of Medical Bibliog. raphy: Panel Discussion," Bulletin of the Medical Li. brary Association, XL (1952), 355-68.

Mr. Clemons is instructor, Library School, Florida State University. systematic search of available literature, and (2) documentation styles, in preparation for thesis writing and other scientific or professional research efforts. Despite constant effort by librarians and others to include adequate instruction on the use of the library in the undergraduate curriculum, the fact remains that many students finish their undergraduate work with only a vague idea of the real potential of library resources. Leaders at FSU deemed it necessary to offer the beginning graduate student an opportunity to overcome this inadequacy. Moreover, foreign students who have not had the experiences of rich library collections and American students who represent the widest possible range of undergraduate experiences, meeting in a common institution with its own requirements of competence, need some formal direction in the examination of research resources and practice in the accepted institutional documentation styles.

Since 1949, L.S. 500, Library Use in Graduate Study and Research, has been a requirement for every student in the graduate school, and one semester hour of credit is granted. Students may satisfy this requirement by completing a departmental course in research methodology. For those who can demonstrate a knowledge of the basic bibliographic sources and styles, competency is recognized through a satisfactory completion of an exemption test. The low percentage of satisfactory completions of this examination, which has been kept gen- 
eral in recognition of the wide variety of subject specialists yet specific in requiring that the student know how and when to use the basic tools, is an indication of the inadequacies presented by beginning graduate students in exploring the research potential of the library. The importance that is attached at Florida State University to competence in conducting library research is illustrated by the action of a faculty committee which refused a request that students in music composition be excused from the course. It was reported by the committee that any student granted an advanced degree, even the concert musician who never contemplated library research, should "know his way around a library."

Dr. Louis Shores, dean of the library school, gave first expression to the need for such a course, and in response to the dean of the graduate school, developed the syllabus. Dean Shores taught the course during its formative years, and even after acquiring the necessary faculty in the library school to teach it, has maintained direction through his interest and enthusiasm. This is not to say that the course has remained the same as in 1948. Instead, it has continually evolved in content through the influences of the many people who have taught it. But the basic considerations, bibliographic sources and styles, have remained the same.

Throughout the history of the course, there has been the concern with dividing students according to the major areas represented by subject specialists. It is felt that effectiveness could be increased if students from the social sciences and the natural sciences were separated. Inroads have been made in the scheduling difficulties which have prevented this, and it is expected that desirable divisions will be in effect soon. One of the major reasons for this division is the distinct difference prevailing in the documentation styles of the two areas.
Since its inception in 1948, the course has been completed by over 1500 students from every area of the curriculum included in the alphabetical range of Accounting to Zoology. A list of all the students who have finished the course is being compiled to show a breakdown of the students from the different subject areas.

Approximately 15 class hours of instruction are required to present the materials included in the course. The technique used for teaching has been to consider a basic type of bibliographic source and to coordinate it with a study and practice of bibliographic styles appropriate for that type of material. Thus the student is able to relate source and style. An examination of book sources would give him an opportunity to practice citations of books, whether he is following the Chicago style, Wister, American Geological Institute, or another. An assignment will require the student to locate books on his subject, copy the bibliographic entry as it appears, and "convert" to the accepted style. This conversion process will enable the student to fix in mind the basic elements common to standard bibliographic description and offer some practice in the style he needs to know to document a thesis or dissertation. When collecting references for papers, students are encouraged to convert the bibliographic information immediately so that this phase of the style problem is overcome at the beginning.

At present the content of the course is organized in 13 units. The following outline indicates the scope:

1. Bibliographic styles. A major consideration is the technique of documenting a paper. Before an examination of sources begins, the basic elements of bibliographic entries are studied through presentation of an "eclectic" form. This involves illustrating the entry with the various elements in a position and with 
punctuation in a manner closely following the styles observed in two common sources: the Library of Congress catalogs and the Wilson periodical indexes. From this middle ground of style students can fix the basic elements in mind, and adapt the form to their particular needs. Concern with bibliographic style is not limited to this unit. It does serve to introduce the problem and prepare the student for the conversion process he must use with succeeding units on books, periodicals, unpublished materials, government publications, etc. Footnote citations are not introduced until it is evident that competency has been gained in listing bibliographic references. This may occur midway in the course, so that the students will have an opportunity to practice writing footnotes in gathering references from some sources.

2. Library card catalogs and classifcation systems. It has been demonstrated that graduate students are frequently stymied in the use of the basic index to the collection, the library card catalog. Since this is the most important source for locating materials, a unit is devoted to the use, potential, arrangement and scope of the catalog, with consideration given to the kinds of information found on the cards and classification schemes, particularly the Dewey system used at Florida State University.

3. Commercially published book sources. Graduate students frequently need books beyond those listed in the local card catalog. In order for them to to determine what has been published in their subject, a unit is presented including the U.S. Catalog, Cumulative Book Index, Publishers' Weekly and the Publishers Trade List Annual as a means of identifying books published in English since 1900. The uses of each are emphasized so the student can relate their values to problems of research in his own subject.
4. National bibliography. Although the catalogs of other national libraries are mentioned as sources for identifying books, primary emphasis is placed on the Library of Congress catalogs of printed cards. Important uses which graduate students may make of this series include approaching materials through subject, as provided by the subject supplement; verifying bibliographic description; locating rare materials; and identifying all the works by authorsto mention only a few. Because the cata$\log$ represents the collection of one of the world's largest libraries, and its cataloging is reputed to be the most accurate and most fully descriptive, it is indispensable for bibliographic work.

5. Periodical indexes and lists. Two or three of the general indexes are generally well known. However, it is appalling that graduate students have so little knowledge of the potential of such indexes as the Education Index, PAIS Bulletin, International Index, Industrial Arts Index, Quarterly Cumulative Index Medicus, Agricultural Index, Engineering Index, and Poole's Index. Most of the students are vague to the point of ignorance about the types of material indexed in each. For instance, many humanities students overlook the Art Index as a source for articles on architecture or archaeology; or the biochemist does not know the Agricultural Index; or the psychology student has never used Quarterly Cumulative Index Medicus. Many students in the natural sciences have depended entirely on the abstract services for article references. Seldom is there evidence that the student is aware of the lists of periodicals such as Ulrich's, Union List of Serials, or the World List of Scientific Periodicals, to say nothing of the value of identifying and locating hundreds of journals dealing with his subject.

6. Abstracts, book reviews and news digests. Students in the natural sciences 
generally make good use of the abstract journals, except for the tendency to depend on only one. The chemist frequently overlooks Biological Abstracts or Science Abstracts, or the physicist overlooks Nuclear Science Abstracts or the Mathematical Reviews. Students in the social sciences have not made such good use of their abstracts, perhaps partly because they are not as prominent nor as comprehensive. But the appearance of abstract journals in economics, history and sociology provides many students with a way to keep abreast of the literature. There is a common misconception among graduate students that book reviews are limited to fiction. A study of the Book Review Digest and other reviewing tools such as the U.S. Quarterly Book Review and the New York Times Book Review introduces sources where the student may get the reaction to a scholarly work as opposed to the detached summary of the abstract. Facts on File and Keesing's Contemporary Archives are examined to make the students aware of sources for locating digests of important news items when needed for reference purposes.

7. Professional and learned societies and their publications. Some time is devoted to this subject because of the vast amount of research activity and the resulting publications of many societies and organizations. Sources are examined which will list the organizations, outline descriptive information and purposes, and disclose research and publications supported $\mathrm{iy}$ learned and professional groups.

8. Locating information on people, places and statistics. Frequently, research workers need biographical information on people whose lives are interwoven with the development of a subject. Presenting biographical sources which include brief identification tools, who's whos, encyclopedic works, and directories which list the membership of learned and professional organizations will enable students to gather the type of biographical information dictated by the needs of his particular research. Some knowledge of the more comprehensive atlases and an acquaintance with sources of statistical information, like the Statistical Abstract, will be helpful in gathering data.

9. Encyclopedias, dictionaries and yearbooks. A common oversight of the graduate student is the use of encyclopedias for authoritative background material and selective bibliographies which may provide a springboard for other references. The yearbooks and annual surveys published in many subjects provide authoritative summaries of the year's progress and developments. Dictionaries in the various subjects are being published in increasing numbers and are a first source for establishing definitions of terms and phrases, a necessity in many theses.

10. Theses, dissertations and other unpublished materials. This is one of the most significant categories of sources for the person who contemplates writing the thesis. He must be sure that he has determined the originality of the problem, and he must be certain that he has exhausted available literature dealing with his problem as contained in other theses and ephemera, in addition to the more conventional sources such as books and journals. Students are very pleased with the results they get through examination of the Association of Research Libraries list and Dissertation Abstracts. In addition, the various subject lists of theses completed and research in progress series which are characteristic of learned journals are valuable aids. The pamphlet material listed in the Vertical File Index is not overlooked in the searching problem, for much of this is of a nature and format that would not be acquired unless a specific need for its use were expressed, which often occurs when the 
specialist is investigating a little known aspect of a subject.

11. Government publications. This type of material is recognized by graduate students to be difficult to uncover, perhaps because of the common practice of organizing and servicing government documents collections separately from other materials. We do not attempt to gain the ease in locating documents that we gain with other materials. Inviting the documents librarian to present a lecture to each class at the scene of the collection, explaining the indexes, and exhibiting representative publications while discussing the overall organization of federal agencies has proved very effective in encouraging the use of the vast amount of publication by official governmental agencies. An alternative method is to discuss in class the types of publications issued by the administrative, legislative, and judicial branches; the arrangement of the Congressional set by serial number, and the departmental publications by the Superintendent of Documents classification schemes; and the historical development and current status of document bibliography. This is complemented by some discussion of state government activity in publishing as identified through use of the Checklist of State Publications. With some knowledge of the organization of agencies doing research in his subject and facility in use of the document indexes, the student can discover pertinent references, even though he will need help to locate them.

12. Audio-visual materials and microphotography. The new audio-visual media of films, slides, recordings, and others too numerous to classify here are presented through an examination of the Wilson guides and the Library of Congress supplements. Especially are these significant to the persons who are concerned with instructional aspects of their subject. A bibliographic style, based on that represented in these sources and the Dugdale manual, ${ }^{3}$ is practiced for this class of material. The microphotographic techniques have been one of the most arresting considerations. We think the research worker needs to be aware of and concerned about the problems of acquiring and storing rare or little used materials. The implications of these techniques as a solution to the manifold problems inherent in the research collection must receive significant emphasis in such a course. More and more, the graduate student will be required to utilize his resources in the form of microreproductions. The various readers are demonstrated, the types of materials reproduced by microphotography are discussed, and the student is prepared to relate the significance and implications of this technique to the literature of his own subject.

13. Library resources and special collections. No meaningful survey of the potential of the research library can be completed without pointing to the libraries with special resources and collections in the various subjects. It is a well recognized and regrettable fact that no university library can hope to acquire all materials necessary for a great research center in all subjects. It is worth while to deal with the movement to survey library collections, which brings to the surface their weaknesses and strengths, and to note some of the implications for scholarship of cooperative acquisition programs. Books which are designed to indicate special resources and collections are examined and students are encouraged to discover those which offer rich collections in their subject.

From the foregoing summary of the content of the course it is evident that

\footnotetext{
3 Kathleen Dugdale, A Manual of Form for Theses and Term Reports (Bloomington, Indiana, 1950), p.53.
} 
in the short time allotted, all sources cannot be treated with as much concentration as may be desired. Students are urged to ferret out those sources which have special implications for their own subjects. At the same time, those sources that cut across all the subjects represented in the curriculum are stressed in the hope that they will become common knowledge among research students.

Student reaction to the course has been favorable. Some students have indicated it to be one of their most valuable, graduate experiences. Although they are quick to admit a lack of understanding about the basic sources, some have questioned the value of the course when it has been delayed until near the end of their program. It is felt that this objection would be eliminated if students would include the course early in their program, as recommended. Others, whose program does not include writing a thesis, feel that it has less value for them. Generally, students have been quick to acknowledge the need for understanding that will permit them to go about searching library resources with ease and confidence.

In addition to teaching some sections of the course, this writer also has the responsibility of editing the theses and dissertations, before acceptance by the graduate school, for style and bibliographic form. This dual role has perhaps resulted in a close relationship between the emphasis of the course and the needs of graduate students regarding research sources and documentation styles. Moreover, it has permitted this writer to observe the effectiveness of indoctrination in sources and style in improved thesis products. Frequent testimony by students indicates the value of the course in locating research materials during their studies in addition to the help it gives them in preparing the manuscript. The influence on the quality of thesis manuscripts is discernible through improvement in investigating research sources and more careful documentation, and perhaps provides the most valid measurement of the effectiveness of the course.

Growing out of the success and general acceptance of the course has been the sharp realization that the use of library resources by undergraduates is inadequate. Graduate students have frequently indicated that the course would have been helpful to them as undergraduates; that such competence need not be considered the province of advanced students to the exclusion of undergraduates.

Awareness of this problem among the faculty in a professional school dealing largely with undergraduates has recently been indicated in a request for the library school to develop and teach a similar course as a requirement in that department's curriculum. This is an encouraging development. Perhaps the influence of L.S. 500 at Florida State University will not be limited to graduate students, but will extend into other undergraduate departments if this experiment at the undergraduate level proves successful. When this awareness becomes sufficiently widespread among other curriculum planners, perhaps the undergraduate can become proficient in the use of library resources. But until that awareness is reflected in the curriculum to include an examination of the basic bibliographic sources, graduate schools must remain concerned about the competence of their students to pursue an independent and exhaustive investigation of the research sources of the library, the common laboratory of all scholarship. 